\title{
Management of Uncertainty in Real Estate Development Appraisals: A Literature Review
}

\author{
Timothy O. Ayodele ${ }^{1}$, and Abel Olaleye ${ }^{2}$
}

1,2 Department of Estate Management, Obafemi Awolowo University, Ile-Ife, Nigeria

To cite this article: Ayodele, T.O., \& Olaleye, A. (2018). Management of Uncertainty in Real Estate Development Appraisals: A Literature Review. Journal of African Real Estate Research, 3(1), pp.94-121. DOI: 10.15641/jarer.v1i1.562.

\begin{abstract}
This paper provides an in-depth examination of various concepts related to the forms and sources of uncertainty, as well as the management of uncertainty in real estate development (RED). The study also examines factors influencing the adoption of Real Option Analysis (ROA) in RED given the need to improve the knowledge of stakeholders in RED appraisal, and to ensure best practices. Based on desktop analysis of past authors' perspectives, orientations and submissions regarding the management of uncertainty in RED appraisal, the findings reveal that while there are varying forms and sources of uncertainty in RED appraisals, there are also diverse methods used to manage the uncertainty of it. It is, however, noted that the methods employed are dependent on RED appraisers and other institutional factors. The consensus from previous studies favours ROA in managing uncertainty in RED. This paper adds to the debate for the need to embrace ROA in managing the effects of uncertainty in RED appraisal.
\end{abstract}

Keywords: Appraisal; Flexibility; Management; Real Estate Development; Real Option; Uncertainty

\section{Introduction}

The nature of investment in real estate by institutional and multinational investors over time has been concentrated largely on direct real estate assets; owing to the seeming prospects and benefits of huge returns (PricewaterhouseCoopers \& the Urban Land Institute, 2013; Ekpenyong, 2015). While real estate investment is fixed both in time and space and involves significant capital outlay, its ability to provide investors with the expected return is subject to an array of sources from which uncertainty

\footnotetext{
1 ayodele.t.oluwafemi@gmail.com; +234 (0) 8067164711

2a olaleye2000@yahoo.co.uk; +234 (0) 8033858591
} 
influences the expectation. Real Estate Development (RED) could thus be regarded as an entrepreneurial activity that involves some measure of risk and uncertainty. In other words, it could be said that risk and uncertainty are integral parts of investment decisions, and the success or failure of RED decisions depend on the assessment and management of the inherent risk and uncertainty. The problem of risk and uncertainty in RED is compounded by new developments in the real estate market which have increased the sophistication of the investors and that of the market itself (Olaleye, 2008). For example, real estate investments are now dominated by institutional investors, while globalisation and Information and Communication Technology (ICT) have improved accessibility to innovative decision tools for RED (PricewaterhouseCoopers, 2014). The investment appraiser must, therefore, manage uncertainty and incorporate it into the financial analysis. This will eventually form the basis of advice for the investor about the investment outlay.

Given this increasing sophistication of investors and the prevalence of risk and uncertainty in real estate markets, RED decisions are becoming more complicated than a "Yes or No" decision criteria. Investors now have the inherent ability to make new decisions at any time for the life of the investment in response to unfolding economic realities, which by their nature are uncertain. Evidence in previous studies has shown that the traditional methods, which have long been used in RED appraisal (Bowman \& Moskowitz, 2001; Copeland, et al., 2010), have been of little practical importance due to the irreversible nature of RED, the presence of uncertainty, and imperfect information (see, for instance, Feinstein \& Lander, 2002; Tomas \& Višić, 2009; Sattarnusart, 2012). In addition, authors have maintained that traditional approaches do not always capture a realistic appraisal of REDs due to their static, accept or reject rule, and do not account for other potential opportunities that investment can generate in the future (Chance \& Peterson, 2002).

Thus, the traditional approaches to RED appraisal are not adequate to serve as decision criteria under uncertain conditions, especially in emerging economies, which typically have greater uncertainty and market volatility. Thus, studies such as Carmichael et al. (2011), and Sattarnusart (2012) have advocated for the adoption of Real Options Analysis (ROA) as a method that incorporates management of uncertainty in RED appraisal. Meanwhile, it is not clear whether or not RED appraisers and other stakeholders (especially in emerging economies) have adequate knowledge of this method. Moreover, in developed markets where the appraisers appear to be aware of ROA, there is a low level of adoption (Andalib et al., 2016). This perhaps may still be the result of an inadequate level of knowledge regarding the inherent advantages of the ROA. With this in mind, this paper gives a global overview of the management of uncertainty in RED appraisal. It provides a comprehensive review of the concepts related to forms, sources, and management of uncertainty and the factors influencing the adoption of real option models in RED appraisal. This is against the backdrop of the need to improve the knowledge of stakeholders in RED appraisal practice and to ensure best practices. 
The subsequent sections of the paper are structured into six sections. The first section focuses on the varying perspectives on risk and uncertainty. This is followed by forms and sources of uncertainty and the management of uncertainty in the second and third sections. The discussions in the fourth and fifth sections were directed towards the types of options and the real options models adopted in RED. The last section examines the factors influencing the adoption of ROA in RED.

\section{Perspectives on Risk and Uncertainty}

There is consensus among existing studies that there are varying perceptions of risk and uncertainty. These variations appear to be dependent on the context in which risk and uncertainty are discussed. Definitions and investigations of the two concepts are explored in different fields, such as: psychology, sociology and economics. This section examines the different definitions in these fields, and the subsequent section directs the conversation towards risk and uncertainty in the real estate sector.

The first perspective is psychological. Slovic and Peters (2006) noted that risk and uncertainty are integral parts of our daily life and are often analysed quickly and spontaneously based on feelings which are usually in the form of experiential thinking. For this perspective, the studies of Slovic et al. (2004) and Slovic and Peters (2006) submitted that risk could be viewed from two perspectives. First as feelings; that is fast, instinctive and intuitive perception of, and reaction to danger. Second, as an analytical process that encompasses logic, reason and scientific methods in the management of risk and decisionmaking processes. Another perspective to risk and uncertainty is the concept of risk as politics. The perception of risk as politics emphasises the influence of power, status, perceived government influence and socio-political factors, among others, in defining the level of risk perception and acceptance (see Slovic, 1999). Furthermore, from a psychological standpoint, Peters and Slovic (1996) and Peters, Burraston and Mertz (2004) argued that risk encompass two dimensions, these are: the dread and the unknown risk. While the first relates to the extent of apparent lack of control, feelings of dread, seeming potential for disaster, and the unequal distribution of risk and benefits, the latter relates to the level to which the hazard is adjudged undetected, new or delayed, resulting in unexpected consequences.

Another standpoint from which risk could be examined is from the perspective of consequentialism. According to Loewenstein et al. (2001), viewing risk from a consequentialist perspective means that decisions are made on the basis of an assessment of consequences of feasible alternatives. This notion of risk relates more to feelings and emotions experienced during the decision-making process. Thus, while the assessment of risk is cognitive, the reaction is emotional. Furthermore, Luhmann (1990: p.225) noted that risk, if measurable, is a counter-concept to security, which is immeasurable. The author defined risk as the "possibility of future damage, exceeding all reasonable costs that are attributed to a decision". Luhmann's study concluded that risk is an avoidable causal link between the time when the 
decision is made and the time of damage, thereby having the prospect of postdecisional regret. It is important to note that risk is an attribute of a decision or indecision, which relates to the level to which probability could be attached to uncertainty about such decisions.

From the perspective of finance and economic literature, the work of Knight (1921) could be regarded as a pioneering study in differentiating between risk and uncertainty in economic theory. The study posited that uncertainty relates to the lack of knowledge about possible outcomes, while risk refers to situations with known alternative outcomes and the attached level of probability associated with each outcome. The study submitted that while risk can be measured numerically, the same cannot be said of uncertainty. Thus, the author concluded that risk could be regarded as measurable uncertainty. While it appears that this position was sufficient to clear the difference between these two terminologies, the study of Pandey (1999) noted that the distinction between risk and uncertainty as submitted by Knight (1921) was not generally recognised in most finance and economic literature; given that the two terms are often used synonymously. Hence, it could be argued that uncertainty is a complex concept with diverse perspectives across varying disciplines, professions and problem domains (Smithson, 2008; Saunders, Gale and Sherry, 2015). However, from a real estate appraisers' perspectives, and perhaps in line with Knight's (1921) position, the study of Byrne (1998) noted that uncertainty is the lack of knowledge about the outcome of a project at the time of making decision, while risk refers to the extent of loss, identified as a probable outcome of a decision.

Uncertainty can also be regarded as the inability to ascertain the exact state of a system (Haimes, 1998); which suggests that probability cannot be measured. Furthermore, Pender (2001) opined that risk applies to situations where there is a probability of repetition and replicability, while uncertainty connotes situations where no prior knowledge exists because replicability and future occurrence cannot be categorised based on past precedence. Thus, it might suffice to note that since each RED is unique and heterogeneous, it is expected that appraisal of REDs would largely involve uncertainty as opposed to risk. This is because each RED comes with its unique conditions and characteristics. It can then be submitted that total ignorance or fundamental uncertainty apply to RED, given that knowledge of future events in relation to the project and other underlying economic inputs are limited.

The study of Ward and Chapman (2003) posited that uncertainty connotes the lack of certainty and refers to the variability in relation to cost, time or quality. It could also be about ambiguity with respect to the lack of certainty due to the attitude of key project actors, lack of data, lack of details, lack of structure to examine issues, lack of sources of bias or ignorance. Uncertainty could also arise when details regarding a system cannot be identified, or, only known without precision (McManus and Hastings, 2005). Given this background, uncertainty could then be regarded as unquantifiable because the consequences are unpredictable (Blokpoel et al., 2005; Reymen et al., 2008). In a similar vein, Perminova et al. (2008) argued that uncertainty refers to a situation where it is impossible to calculate the risk inherent in an outlay. 
Hence, risk has the ability to assume the probability of occurrence, and it is seen as less threatening to investment decisions as compared to uncertainty in which the probability of occurrence is unknown. A study by Loizou and French (2012) posited that where probability can be attached to the input variables, that is, the ability to determine a range of possible outcomes, such an output is thus a measure of risk. Risk can then be regarded as the deviation from the central tendency, for which the outcomes may or may not occur due to imperfect information about the future.

Employing the uncertainty spectrum framework of Hargitay and Yu (1993), the authors noted that uncertainty could be regarded as either partial or total. Total uncertainty arises where the alternatives cannot be identified, while partial uncertainty relates to situations where the alternatives can be identified, but not with predictability or probability. However, where there are identifiable alternatives with a measure of predictability and probability, such scenarios refer to risk.

Thus, it presupposes that uncertainty primarily arises due to lack of knowledge and imperfect information leading to inability to predict all variable inputs required for informed decision-making. Thus, uncertainty is a fact which all decision makers must contend with. It arises as a result of ignorance with respect to the state of knowledge, and/or lack of control (Kahneman \& Tversky, 1982). It can be regarded as an unpredictable and/or uncontrollable risk.

\section{Forms and Sources of Uncertainty in Real Estate Development}

Economic, physical, and political environments, among others, all within which RED is situated, are subject to an array of influences that introduces uncertainty to the core of all RED activities. Stakeholders also play a role in influencing RED within these environments. Thus, uncertainty in RED can take on different forms and could arise from different sources. However, Kahneman and Tversky (1982) noted that while probability can be used to express forms of uncertainty, the laws of probability cannot be applied to all variants of uncertainty in equal proportion. The laws of probability are often satisfied based on intuitive judgement, especially when an external source of uncertainty is assessed in a distributional mode. An examination of these forms and sources is the focus of the subsequent subsections.

\subsection{Forms of Uncertainty}

Extant studies suggest that forms of uncertainty are broadly grouped into two categories. These are epistemic uncertainty and aleatoric uncertainty.

\section{a. Epistemic Uncertainty}

Epistemic uncertainty is derived from the Greek word episteme meaning knowledge. It arises from insufficient knowledge about possible outcomes, the nature of outcomes and the associated probabilities (Yeo, 2012). Epistemic uncertainty could be reduced in principle with the passage of time and the availability of more information. Thus, this kind of uncertainty arises 
from incomplete theory and imperfect understanding of a system or limited data. Epistemic uncertainty could also be referred to as internal, imprecision, functional, subjective, reducible or a model form uncertainty (Hillson, 2004; Chalupnik et al., 2009; Yeo, 2012). As such, with regards to RED, epistemic uncertainty relates to instances such as dated, missing, vague or incomplete information, incorrect assumptions and unexpected changes in socioeconomic variables.

\section{b. Aleatoric Uncertainty}

Aleatoric uncertainty, from the Latin root, aleator - dice thrower; or alea dice, refers to inherent variability, chance, randomness or unpredictability. It arises due to natural, unpredictable variation or randomness in the performance of a process (Yeo, 2012). It is irreducible. Obtaining more knowledge cannot eliminate inherent variability. Aleatoric uncertainty, sometimes associated with variability, could also be termed as natural variability, irreducible uncertainty, stochastic uncertainty and random uncertainty (Chalupnik et al., 2009; Yeo, 2012). Aleatoric uncertainty connotes the knowledge of a range of a possible set of outcomes and the probability attached to each can be measured. However, the precise outcome at any instance is unknown. Aleatoric uncertainty is often represented in stochastic terms and reasoned out using probability theory (Hillson, 2004; Aughenbaugh \& Paredis, 2006). With recourse to RED, aleatoric uncertainty encompasses uncertainty arising from sources such as environmental, social complexity and change in physical environment.

Given that processes involving random behaviour exhibiting unpredictability are referred to as a stochastic process; the outcomes of such a process are dynamic from time to time and place to place, even when other basic elements are held constant. The RED process similarly exhibits such stochastic nature; however, its basic features are not constant. Thus, RED could be regarded as a more complex stochastic process whose features vary with time, place and variable inputs. This presupposes that when there is the inability to ascertain the validity of variable input in the RED, the resulting outcome of the appraisal might become uncertain leading to loss of capital or investment.

This presupposes that the two aforementioned forms of uncertainty are broader perspectives from which sources of uncertainty can be examined. An examination of these sources of uncertainty is discussed subsequently in order to show a detailed perspective as to how these two forms of uncertainty influence RED.

\subsection{Sources of Uncertainty}

Uncertainty lies at the root of all RED projects, and its sources are varied. Hillson (2004) noted that real estate projects are subject to uncertainty from a multiplicity of sources that can be either internal or external to the project, and these range from technical, to management, to operational and to commercial uncertainty. Internal sources relate to either the actual work to be done (such as changing work requirements/scope, wrong or flawed assumptions, and new technologies/methods), or stakeholders involved in the project (such as varying skills/productivity and performance of team 
members). External sources encompass issues such as project environment, market condition, the action of competitors, change in exchange/inflation rates, weather conditions and influence of other stakeholders. From a related perspective, Reymen et al. (2008) posited that uncertainty in relation to RED could be addressed from two significant perspectives; these are cause and consequence. The causes relate to the unpredictability of input variables (data and values), while the consequences relate to uncontrollability of decisions made by the team members, especially the investor or project appraiser.

Corroborating previous discussions, Chalupnik et al. (2009) noted that two sources of uncertainty could be identified in the development process. The first is exogenous uncertainty, relating to unknown variables in the external environment of the RED. The second is endogenous uncertainty, which relates to the unknown internal factors embedded in the RED. Exogenous uncertainty explains the uncertainty whose source arises from the external project environment. This external uncertainty can arise because of change in organizational structure, volatility/unpredictability of economic variables, changes in user's taste, or due to the dynamism of political and cultural setup of the RED company. Endogenous uncertainty whose source is internal to the RED can further be examined from two perspectives. The first is the uncertainty associated with the technological novelty dimension, which could be because of product or process technological novelty. The second relates to the process complexity dimension. This pertains to the challenges that are unique to achieving the process objectives, the innovation of the objectives to the RED company and the level of interdependency among the product element.

Further, the study of Yeo (2012) posited that uncertainty results from two distinct sources: natural variability and knowledge uncertainty. The former, which relates to the macro level, arises due to decision-making in a dynamic and uncertain environment. The latter, which is at the micro-level, relates to particular scenarios with respect to knowledge, data and models used in the RED appraisal. Uncertainty at the macro-level impacts RED investment decisions through a continuously and swiftly changing social and economic environment, while micro level uncertainty concerns specific details in the project at the level of available knowledge. Akakandelwa (2014) argued that RED is prone to volatilities from varying sources, such as the demand for space for economic activities, to the influence of technology and the level of vibrancy of the space market.

Perhaps from what appears as a more detailed perspective, Saunder et al. (2015) noted that sources of uncertainty could be grouped into five (5) broad perspectives, namely: environmental, individual, complexity, information and temporal perspectives.

Sources of uncertainty from the environmental perspective include factors such as turbulence of the environment, institutional norms, the process of decision-making, competitor threats, external industry and market risks.

The individual sources encompass factors like internal state of understanding, uncertainty existing in the mind of the individual and the differing perception of varying psychological profiles towards uncertainty. 
The complexity dimension emphasises factors such as choice of technology, process actors, diversity of process stakeholders and inherent project complexity.

For the latter two; information and temporal, the sources of uncertainty with respect to information perspective arises due to incomplete and imperfect information, lack of knowledge, incomplete understanding of cause and effect and inability to arrive at accurate project estimates. Temporal source involves the stage of project life cycle, project tempo and scale of project turbulence.

This presupposes that uncertainty is an integral part of the RED appraisal and can arise from either the project environment or from the economic environment wherein the RED situates. Uncertainty from the project environment includes instances such as the influence of project stakeholders, project scope, the level of technology required and varying psychological profiles, among others. Uncertainty from economic environments include, but not limited to: market data, market risk, volatility of economic variables, and incomplete information (Saunders et al., 2015). This paper thus argues that in order to ensure that the investor's goal of profit maximisation is achieved, there is a need to adequately manage these sources of uncertainty.

\section{Management of Uncertainty in RED}

Studies have investigated the management of uncertainty in relation to general investment decisions and in particular to RED. Bannerman (1993) noted that results of appraisal in emerging countries, when compared to developed economies, are often difficult to rely on and justify. This owes to the fact that high fluctuations and volatility with respect to market data, and other input variables in most emerging markets have some overbearing influence on the reliability of the appraisal estimates and guarantee of investors profitability. Hence, the issue of managing uncertainty comes to the fore, especially in emerging markets. The management of uncertainty can be done in a number of ways; however, these are broadly divided into three categories. They include traditional, probabilistic and contemporary appraisal methods. An examination of these approaches is undertaken hereafter.

\subsection{Traditional Appraisal Techniques}

While there are varieties of traditional investment evaluation tools in the portfolio of an investment appraiser, traditional techniques could be broadly grouped into non-discounting and discounting appraisal methods. The nondiscounting investment appraisal methods include techniques such as; payback period, accounting rate of return, and maximum cash exposure. The discounting methods encompass methods like Net Present Value (NPV), Internal Rate of Return (IRR) and profitability index among others. These are also regarded as variants of the Discounted Cash Flow (DCF) technique, and are commonly employed in determining future cash flows, and often serve as the basis for assessing investment values (Chance \& Peterson, 2002).

Authors such as Trigeorgis (1993), Walters and Giles (2000) and Carmichael et al. (2011) have noted that the use of the traditional models in appraising irreversible investment such as RED do not consider the strategic importance 
of an investor's flexibility in revising or altering decisions after the commencement of the project, and investment capital is seen as being passively held. Thus, the models cannot address the problem of uncertainty adequately in the RED appraisal. For instance, investment appraisers using the traditional models assume that once the project commences operation, it will continuously generate income without interruption until the RED is decommissioned (Slade, 2001; Yeo \& Qiu, 2003). However, given the level of uncertainty in the future, this assumption is seldom possible.

In general, traditional investment models have not adequately emphasised the implications of the relationships between irreversibility, uncertainty and timing choice in investment decisions. Hence, with the resultant criticism highlighting that most investments are more sensitive to issues of volatility and uncertainty in the economic environment over a longer period of time, the adoption of traditional models in appraising RED might not be justified (Dixit \& Pindyck, 1994). Mun (2006), while summarising the critique of the use of traditional investment appraisal methods, noted that the models undervalue assets that presently produce little or zero cash flow. Other critiques are the non-consistency of the average cost of capital or discount rate during the investment period, wrong estimates of an asset's economic life, forecast errors in calculating future cash flows, and inadequate test for reasonableness of the final value estimates.

Traditional theories of investment under uncertainty employ static decision rules on whether to invest or not. Where the project's expected NPV is positive, a higher IRR, or quicker payback period, the decision to invest is favourable. However, if these markers are not met, the decision to invest is not encouraged. This is tantamount to determining the present values of investment before they are received, and that the investment decision is allor-nothing, 'yes-or-no'. This leaves no allowance for an initial decision, followed by other subsequent decisions based on unfolding future events. However, in the face of realistic assumptions, an investment with a negative NPV, lower IRR or an extended payback period - based on current realities might subsequently have a positive NPV, higher IRR or shorter payback period when economic parameters and other input variables are more favourable. This raises the problem of uncertainty and underscores the need for flexibility, to be incorporated in the traditional appraisal models.

Given that investment appraisal methods are expected to reflect flexibility and strategic value as important components that contribute substantially to the value of the project in an uncertain market environment, the traditional approach will not explicitly evaluate the value of flexibility embedded in an investment outlay (Chance \& Peterson, 2002; Trigeorgis \& Smith, 2004). The traditional models are often skewed and fail to give a thorough perspective of the investment value of the project, thus giving rise to the possibility of an undervalued investment (Block, 2007). It therefore, presupposes that the assumptions underlying the traditional models might lead to unreliability of the appraisal estimates, due to its static one-time decision. 
As a consequence, traditional models might not be a sufficient basis to advise investors given the tendency for wrong investment decisions. This is due to the irreversible nature of most investments and the inherent ability to exercise a delay or postpone investment decisions, which lies at the discretion of the investor. Hence, the concept of irreversibility undermines the theoretical underpinnings of the neoclassical investment theories and invalidates the traditional decision rule. Thus, irreversibility makes investment sensitive to various forms of uncertainty over prospects which the traditional models fail to adequately incorporate (Pindyck, 1991).

However, it must be noted that the above is not underplaying the importance of the traditional-based approaches in evaluating safe assets and investment decisions in an environment of certainty and stability of input variables. If all uncertainties are cleared, and all options are known at the commencement of the project and can be accurately evaluated, traditional appraisal models can be used with precision, but this is rarely the case. Thus, the models usually fail to account adequately for uncertainty and pricing of flexibility entrenched in the valuation of risky investments (Slade, 2001; Mun, 2002). Arising from the inability of the traditional investment appraisal models to adequately value flexibility, probabilistic techniques were proposed as a means of enhancing the reliability of appraisal estimates obtained from the traditional models.

\subsection{Probabilistic Appraisal Techniques}

Probabilistic techniques appear to be somewhat of a departure from the conventional, traditional approaches employed in investment appraisal. These techniques, though do not provide a thorough evaluation of the various options available to the investor; afford some form of insights into likely options/pathways in making optimal investment decisions.

Probabilistic techniques encompass methods such as sensitivity analysis, simulation analysis, and decision trees analysis, among others. However, these probabilistic techniques do not recognise the inherent opportunity to modify investment outlays (Brealey et al., 2012). Also, while sensitivity and simulation analysis could be used in evaluating the available opportunities by clearly presenting possible outcomes of a decision, they do not provide optimal guidance concerning which course of action would guarantee the investors optimal returns. Thus, while sensitivity analysis allows for assessing the effects of changes in a factor on projects' estimated values, simulation analysis allows for multi-factor random variance. Both methods allow for some form of changes in factors but do not holistically capture the options that are embedded in an investment project (Chance \& Peterson, 2002).

With respect to the decision tree, though it provides a mapping of alternative options, the use of a single discount rate negates the reality that the rates fluctuate over the life of the investment (Chance \& Peterson, 2002). It also fails to capture the "real" values of the available options. Thus, traditional valuation models can be enhanced with the use of probabilistic techniques as 
it incorporates some flexibility. However, this model tends to complicate the results and diminish their interpretive decision-making character (Chance \& Peterson, 2002). Furthermore, caution needs to be applied if the variables are to be tested in combination during the sensitivity analysis (Raftery, 2003). Thus, though the probabilistic techniques appear to offer some form of assistance in managing uncertainty in RED; contemporary appraisal techniques, such as the option pricing framework, provides a more robust, real and comprehensive method of analysis.

\subsection{Contemporary Appraisal Techniques}

Several contemporary methods have been proposed in the literature to manage uncertainty in RED. In what appears to be a descriptive perspective, the study of Ward and Chapman (2003) advocated for the use of a holistic approach in handling uncertainty in projects. This approach takes into account a careful analysis of project design, base plans, nature of project stakeholders and their investment objectives. However, given that this approach lacks quantitative analysis, its adoption in managing uncertainty in RED appraisal might best be complemented with other contemporary quantitative methods. The study of Blokpoel et al. (2005) and Reyman et al. (2008) suggests the use of the scrum-based framework. The scrum-based process developed by Schwaber and Sutherland (Schwaber, 1996; Schwaber \& Beedle, 2002) is an iterative, incremental framework used in project management. While the scrum process was initially developed for managing product development projects, it has been applied to other areas, such as the management of software development projects, software maintenance teams, and recently in project/program management (Cho, 2008; Lina \& Dan, 2012).

Additionally, Ustinovičius et al. (2007) proposed the adoption of stochastic programming in minimising the effects of uncertainty at the various phases of the RED project. Furthermore, the study of Yeo and Qui (2003) argued for the need to adopt the real options framework as a means of managing uncertainty in RED. Corroborating this perspective, the study of Săcui and Dumitru (2012) argued that given the deficiency of traditional models to manage uncertainty in RED arising from the dynamic and uncertain business environment, real options approach has become dominant in valuing, selecting, and managing strategic investments under uncertainty. Other studies, such as Throupe et al. (2012), Morano et al. (2014), corroborated this assertion of the efficiency of the real options approaches as a means of managing uncertainty in RED projects. Hence, other contemporary methods can be employed to manage uncertainty in RED as suggested in the literature, the use of real option models has come to the fore. The focus of the next section is to discuss the various options available in RED. Table 1 provides a summary of the various techniques used in the management of uncertainty. 
Table 1. Techniques for Management of Uncertainty in RED

\begin{tabular}{|c|c|c|c|}
\hline Techniques & Methods & Benefits & Critiques \\
\hline $\begin{array}{l}\text { Traditional } \\
\text { Appraisal } \\
\text { Methods }\end{array}$ & $\begin{array}{l}\text { 1. Non-discounting } \\
\text { (Payback period, } \\
\text { Accounting rate of } \\
\text { return, maximum cash } \\
\text { exposure, etc.) } \\
\text { 2. Discounting (NPV, } \\
\text { IRR) }\end{array}$ & $\begin{array}{l}\text { 1. Useful in appraising } \\
\text { safe assets } \\
\text { 2. Simplicity in } \\
\text { calculation and decision } \\
\text { rules } \\
\text { 3. Makes use of fewer } \\
\text { data inputs }\end{array}$ & $\begin{array}{l}\text { 1. Does not adequately explore the } \\
\text { implications of the relationship } \\
\text { between irreversibility, } \\
\text { uncertainty and timing choice. } \\
\text { 2. Do not consider the strategic } \\
\text { importance of investors flexibility } \\
\text { after commencement of the } \\
\text { project } \\
\text { 3. Investment capital is regarded as } \\
\text { being passively held } \\
\text { 4. Non-consistency of the average } \\
\text { cost of capital/discount rate }\end{array}$ \\
\hline $\begin{array}{l}\text { Probabilistic } \\
\text { Appraisal } \\
\text { Methods }\end{array}$ & $\begin{array}{l}\text { 1. Sensitivity Analysis } \\
\text { 2. Simulation Analysis } \\
\text { 3. Decision Tree } \\
\text { Analysis, etc. }\end{array}$ & $\begin{array}{l}\text { 1. Afford some insights } \\
\text { into likely options/ } \\
\text { pathways }\end{array}$ & $\begin{array}{l}\text { 1. Does not recognize the inherent } \\
\text { opportunity to modify investment } \\
\text { outlays } \\
\text { 2. Does not provide optimal } \\
\text { guidance concerning which course } \\
\text { of action will guarantee optimal } \\
\text { returns } \\
\text { 3. Use of single discount rate }\end{array}$ \\
\hline $\begin{array}{l}\text { Contemporary } \\
\text { Appraisal } \\
\text { Methods }\end{array}$ & $\begin{array}{l}\text { 1. Scrum based } \\
\text { framework } \\
\text { 2. Stochastic } \\
\text { Programming } \\
\text { 3. Real Options } \\
\text { Analysis, etc. }\end{array}$ & $\begin{array}{l}\text { 1. Provide ability to } \\
\text { introduce flexibility } \\
\text { into the investment } \\
\text { project, especially in } \\
\text { unstable markets. } \\
\text { 2. Explores the } \\
\text { relationship among } \\
\text { irreversibility, } \\
\text { uncertainty and timing } \\
\text { choice of the investor }\end{array}$ & $\begin{array}{l}\text { 1. Tendencies for miscalculations } \\
\text { and/or misinterpretation of } \\
\text { appraisal estimate } \\
\text { 2. Susceptibility to model risk } \\
\text { 3. Failure to meet assumptions } \\
\text { such as lognormality, randomness, } \\
\text { etc. } \\
\text { 4. Might not be encouraged in } \\
\text { markets where there are no } \\
\text { sufficient input data. }\end{array}$ \\
\hline
\end{tabular}

\section{Types of Options in Real Estate Development}

Each real option type as discussed in the literature is aimed at mitigating losses and enhancing profitability of RED. However, note that not all RED has option value, and for those that do, each of the options must be carefully considered based on the context of the RED, with the understanding that each RED project is heterogeneous in nature. Săcui and Dumitru (2012) submitted that real options can be broadly differentiated into two groups namely, inherent and created options. While inherent options are also known as control options, they are characterised by the fact that they do not require special activities; they are only observed. Examples of such options include: deferring, waiting, abandoning and expansion of a project. A major characteristic of such options is the ability to identify and utilise the options. Created options refer to those options that require intentional and well thought out actions for their creation and maintenance. The investment appraiser takes 
into consideration possible evolution of future events while creating such options.

The application of real options to RED takes on different perspectives in literature. Studies such as Sattarnusart (2012) and Smit and Trigeorgis (2003) noted that the option to defer investment applies more to RED than all other options, or perhaps to the exclusion of other options. Kumar (2016) noted that there are three main types of options particular to RED. These are: option to postpone or delay, the option to expand, and option to abandon. Further, Brandao and Dyer (2003) posited that typical RED options include, phasing, abandoning and waiting. While other studies such as Barman and Nash (2007), Guma (2008), Kim (2008), Pearson and Wittels (2008) and Cailao (2009) have investigated the application of an option or a multitude of options on RED. These include vertical expansion/phasing, switching, deferring and abandoning. Thus, it appears that the argument as to which of these options readily applies to RED might be well-situated in the context of the type, scale and scope of the RED project, and perhaps the national and regional regulatory environment. Thus, though different studies have suggested varying classifications/groupings of the types of real options applicable in RED projects, given the simplicity and robustness of Masunaga (2007) and Cailao (2009) in discussing the various types of options as applicable to RED decisions, this study adopted their classification of real options as described below.

\subsection{Growth/Phasing Option}

The growth/phasing option could also be referred to as the expansion option. It is one of the common types of options in use, especially in a growing and thriving economy (Chance \& Peterson, 2002). Where there is good economic outlook and favourable market conditions, investors seek to increase possible profits. A phasing option arises when the developer builds an initial phase and waits to observe the performance of the market before commencing subsequent phases. If the first stage is viable and successful, the development is continued and expanded. The developer, being profit-driven, subsequently seeks to reduce the risk by dividing the project into separate phases by delaying or cancelling additional phases; if they do not guarantee commensurate returns on investment at a future date. When an investment has a growth option, it implies that the investor has the opportunity to add more funds and expand the project's scale. Trigeorgis and Smith (2004) posited that the higher the growth/expansion option, the higher the market value of the investment. However, this may appear excessive based on the standard DCF appraisal methods.

Hence, given the existence and value of growth options, an investor may choose to embark on the initial phase despite seemingly adverse outcomes. The unfolding success or failure of the initial phase determines if the subsequent phases would be embarked upon (Cailao, 2009; Săcui \& Dumitru, 2012). 


\subsection{Deferment/Waiting Options}

The case for deferral is made when considerable value can be gained by waiting to resolve some forms of uncertainty associated with the project or investment environment. The investor can choose to stay put or suspend investment due to doubt about future opportunities, or when there is uncertainty about major inputs in the investment decision. Thus, the investor might be buying time for the investment outlay in anticipation that the unfolding developments become favourable in the near future (Săcui \& Dumitru 2012). This suggests that a period is allowed for analysing the market/investment environment and to grasp the unfolding market conditions better. Thus, some projects are not necessarily needed to be commenced or initiated now, given the prevailing market circumstances. Although it might be expected that waiting might give competitors some form of early lead in terms of market entry, it has the potential to expose previously unknown information about the market dynamics. For instance, an investor may wait for markets to recover from a downturn or wait for some amendment/changes in unfavourable government policies with respect to certain developments before embarking on the development in anticipation of favourable potential.

With respect to RED projects, an investor's decision to construct/develop might be deferred to wait and see if market rental values would justify construction/development (Yeo \& Qiu, 2003; Cailao, 2009). According to Kandel and Pearson (2002), under uncertain conditions, investors are predisposed to wait rather than commit. Thus, under a more realistic scenario, the option to wait is a preferred alternative to investing or not investing, as opposed to the traditional decision to accept or reject. An argument in favour of the dynamism of investment timing, as opposed to static accept/reject rule, is that, due to the irreversible nature of RED projects, the more rational behaviour is withholding investment until much of the uncertainty is eliminated (Rodrik, 1991). Thus, it appears that uncertainty with RED naturally stimulates the value in waiting due to the huge financial investment and irreversible nature of real estate investments.

\subsection{Exit/Abandonment Options}

Where conditions in the market deteriorate severely during the economic life of a project, an investor can decide to abandon the project out-right by not investing any further in it. This option is aimed at cutting losses and it gives the investor the option to abandon the project midway, given that new information is unfavourable for continuing the project (Masunaga, 2007; Cailao, 2009). Some options to abandon give the investor the opportunity to dispose of the project and realise the salvage/resale value of previous capital investments made in the project. However, before the investor considers the option to exit, there might need to examine existing legal implications. Hence, the option to exit only becomes ideal in a RED when the reality of obvious risk becomes apparent and there is no legal implication for such default option. In the case of RED, the owner of vacant land exercises the exit option when he sells the land without building on it (Chance \& Peterson, 2002; Săcui \& Dumitru, 2012). 


\subsection{Learning Options}

Learning options are akin to phasing and deferment options. However, in this instance, the investor might explore the suitability of the project by embarking on the development of the initial phase, perhaps, with low costs. Subsequently, the outcome can help the investor decide on whether to modify or abandon the other phases to minimise loss and maximise the total value of the project. Thus, the initial phase serves as a pilot study for the investor to understudy the market and other economic variables associated with the development (Masunaga, 2007; Cailao, 2009). Mun (2006) noted that learning models are a part of real options, as management makes superior strategic decisions with the passage of time and uncertainty is resolved.

\subsection{Modify/Switching Options}

Perhaps due to fluctuating economic variables leading to changes in market prices or consumer demand, the investor can decide to alter the output mix (product flexibility) or maintain the same output but different input (process flexibility) (Tamayo-Torres et al., 2010). This option is often embedded in the initial project design. Thus, with respect to RED projects, instances such as conversion, alteration or modification, are examples of switching options. It affords the investor the opportunity to modify existing project design to suit new uses arising from a change in market demand and preferences. For instance, the appraiser might advise the investor to switch from hotels to apartment houses or from residential to office building and vice versa, given the unfolding realities of the market (Masunaga, 2007; Cailao, 2009).

Other types of options within the ambit of the classification adopted for this study include the option to contract. Contracting options arise when the economic outlook appears less favourable than anticipated. The investor can decide to reduce the project's scale (contract), and on the extreme, the development may be halted temporarily and start up later (Chance \& Peterson, 2002). This form of option is combined with the option to delay initial investment and reduce the scale of the project, which is a contrast to the growth option.

The aforementioned opportunities connote real options that allow the investor the opportunity to enhance the project's value. This value cannot be determined using traditional DCF models, instead it can be derived through ROA. The real options framework presents a similar flexible pathway for its holders to decide whether to wait, invest or defer, although the choice of exercising any of these options is dependent on prevailing market conditions and the stage of the RED. Thus, as noted by Barman and Nash (2007), the investor exercises flexibility when there is an adjustment/modification to the existing course of action, resulting from changes in the economy and/or project as long as there is no prior commitment or downside risk of exposure. However, it must be noted that real options as discussed above are related to each other, given that RED projects can feature more than one real option simultaneously. 


\section{Real Option Models}

Current literature suggests different categorisations of modelling approaches used in ROA (see, for instance, Miller \& Park, 2002; Guma, 2008; and Peter, 2012). However, this study adopted the categorization employed by Miller and Park (2002) owing to its simplicity and clarity.

Miller and Park (2002) noted that there are two broad approaches employed in the valuation of real options. They are the discrete time approach and the continuous time approach. While a variant of the discrete time approach includes multinomial lattices, models under the continuous time approach are the closed form equations, stochastic differential equations and the simulation models. A comparison of the advantages and disadvantages of each approach is shown in Figure 1, as adapted from Miller and Park (2002).

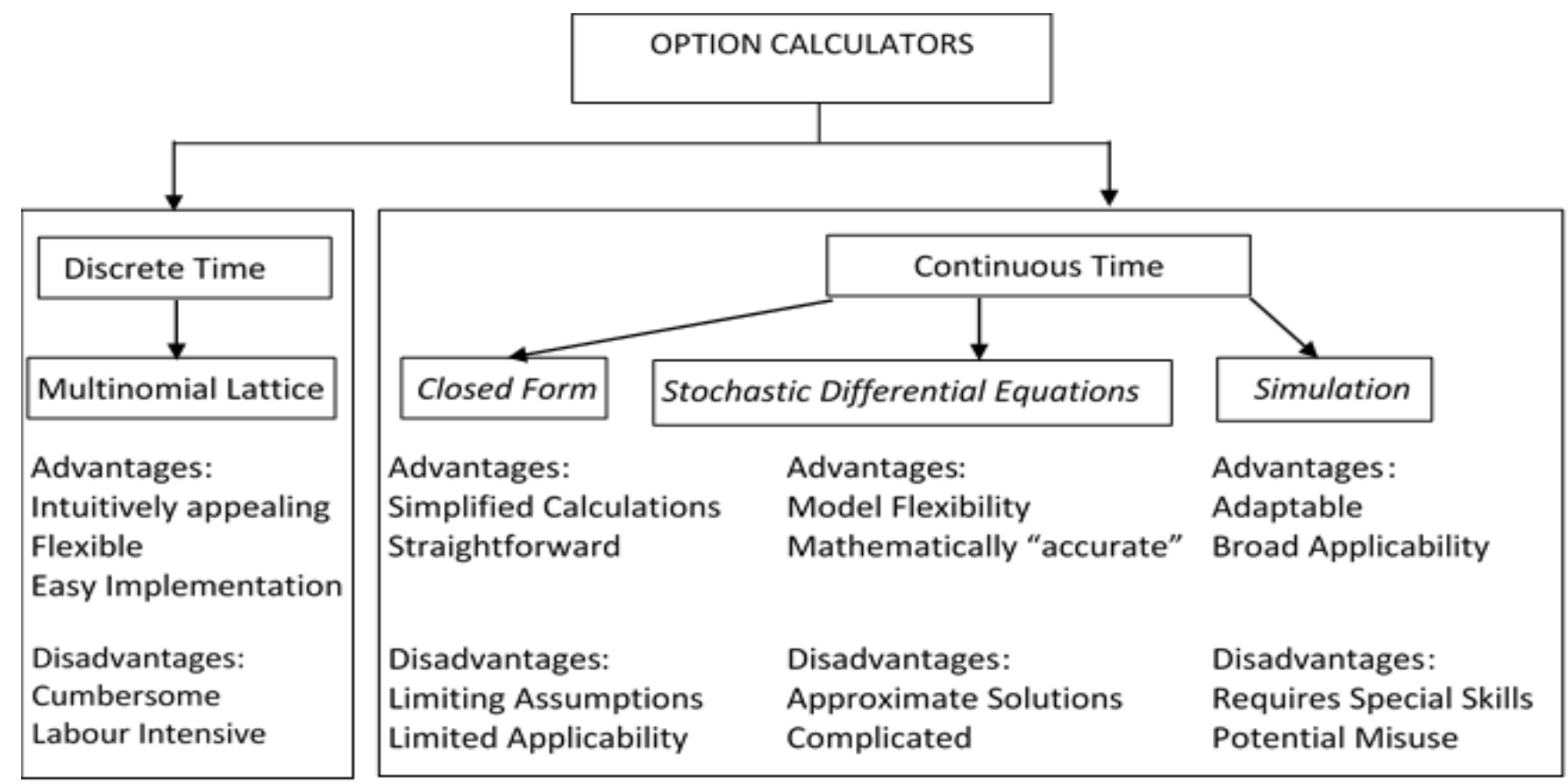

Figure 1: Flexibility Analysis Modelling Approaches (adapted from Miller and Park, 2002)

\subsection{Multinomial Lattice Approach}

The lattice approach is premised on the assumption that the underlying assets follow a discrete multinomial, multiplicative stochastic process all through time to develop a "tree". The binomial model; a variant of the multinomial lattice approach, was developed by Cox, Ross and Rubinstein (1979).

Masunaga (2007) noted that the assumptions underlying the binomial approach are: the existence of a perfect market, complete markets, rational behaviour, and Geometric Brownian motion. Under the binomial model, the lifespan of the option is broken down into multiple time steps, resulting in several up or down movements of the underlying assets; thus, creating a tree of likely possibilities for the underlying assets. The option value is then 
obtained by working the tree backward from the end to the starting point. At each node, the option value is determined, while taking into consideration the state of the underlying assets and possible states one level ahead (Peter, 2012). Though the binomial approach appears similar to the framework being employed by the decision tree analysis, the binomial approach, however, does not require the knowledge of discount rates that reflect the risks or actual probabilities of outcomes as employed under the decision tree framework (Chance \& Peterson, 2002).

Masunaga (2007) posited that the binomial model has several advantages over other option models, given that it illustrates midway decision-making process between the initial time and the unexpired time of the option. This enables the appraiser, to understand decision criteria at each point in time intuitively, and the tree structure supports delay, growth and contraction option (Miller \& Park, 2002). Peter (2012) further noted that another advantage of the method lies in the use of probabilities to account for the riskiness of the payout structure and not the use of a discount rate. Thus, risk and time value of money are separated. However, a drawback of the model, according to Peter (2012), is its inability to draw meaningful conclusions because the results cannot be easily retraced in the model. Another critique according to Cailao (2009) is that the model constrains development timing to a finite span of time. As such, it cannot be used to value perpetual option of developing on a land with fee simple ownership. Thus, a major demerit of the approach is in its ability to value only finite-live options. The approach failed to consider time as a continuous component, rather as discrete steps.

\subsection{The Closed Form Solutions}

There are ranges of closed-form solutions such as the Black-Scholes (Black \& Scholes, 1973) or Samuelson-McKean formula (Samuelson, 1965; McKean, 1965). Miller and Park (2002) noted that other closed form solutions used in ROA include Margrabe, Geske and Carr. The Margrabe model developed by Margrabe in 1978 was developed to value the option of exchanging one asset for another. Also, Geske in 1979 proposed an equation to value compound options having a deterministic exercise price. The model applies to sequential investment options, especially in research and development. Finally, Carr in 1988 developed a compound option equation with stochastic exercise prices. However, the Black-Scholes and the Samuelson-McKean formula have enjoyed wide acceptability. The BlackScholes model is typically used in valuing stocks and other financial assets, while the Samuelson-McKean formula is best suited for real estate assets (Peter, 2012). Geltner and Miller (2001) noted that the Samuelson-McKean model is the Black-Scholes formula for calculating real option value of real estate assets.

\section{a. Black-Scholes Model}

The Black-Scholes model was developed by Fischer Black, Myron Scholes (Black \& Scholes, 1973) and Robert Merton (Merton, 1973). It relates five factors in determining the option value of an asset. These are the underlying price of the asset, the exercise or strike price of the option, continuously 
compounded risk-free rate, assets volatility, and time to expiration in years. The Black-Scholes model is one of the many models of the partial differential method. Masunaga (2007) noted that the model is a ground-breaking work due to its ability to use dynamic tracking approach under the no-arbitrage framework.

Masunaga (2007) highlights that a significant advantage of the model is its speed of computation which provides the foundation on which other recently developed techniques of real options valuation rely upon (Chance \& Peterson, 2002). However, aside from the fact that it cannot be employed for options with dividend payment and compound options, it might not always be best suited to valuing options in real estate developments. This is owing to the fact that it may not always readily provide the option value and cannot give solutions to more complicated real options with infinite life, exercisable at any time (Chance \& Peterson, 2002; Masunaga, 2007).

\section{b. Samuelson-McKean Model}

Paul Samuelson and Henry McKean developed the Samuelson-McKean model. The method leverages the deficiency of the Binomial model. It can be used to analyse the perpetual development option incorporating continuous time. Given that interest in land could be held perpetually, the formula affords a means of evaluating endless options under continuous timing (Guma, 2008).

The input variables required for the Samuelson-McKean model are the current value of the underlying assets, the cost of construction, volatility of the built property value, built property cash yield rate, risk-free rate, and construction cost yield - approximated by differencing the risk-free and the growth in construction costs. The Samuelson-McKean model is more suitable in valuing RED options than other closed form solutions such as the BlackScholes model (Geltner, 2007), given that the right to develop on land is regarded as infinite (Kim, 2008).

Barman and Nash (2007) posited that the closed form solutions, that is, the Samuelson-McKean and the Black-Scholes are premised on the same underpinnings of economic arbitrage. They are based on the assumptions of efficient real estate markets, random walk theory, normal distribution of returns, riskless construction costs, and constant growth rate. Peter (2012) noted that it might be challenging to estimate and clearly communicate the meaning of results obtained from the closed form solutions because the model produces only one specific number that must be interpreted with extreme caution. In addition, it is prone to the use of wrong models or inferring wrong conclusions if the underlying assumptions are not clearly understood by the appraiser. Furthermore, the author noted that another deficiency lies in its inability to value complex payout structures. The models only allow for one kind of option within a project and cannot accommodate interplay of multiple options. Thus, given that RED is open to an array of several options, the applicability of the closed-form solutions is limited to an examination of only one type of option at any particular time. Masunaga (2007) noted that an advantage of the discrete and closed form approaches is that they are based on the risk-neutral framework. Hence, these models do not require risk- 
adjusted discount rates, the need for which seems challenging in the valuation of real options.

\subsection{Stochastic Differential Equations}

The stochastic differential equations are used in deriving the closed form equations. Thus, a series of stochastic differential equations with boundary conditions are first solved. Often, however, the stochastic differential equations solution does not exist, and the partial differential equations are then solved using finite difference methods or Monte Carlo simulation. From a real options perspective, it is still pertinent to obtain a set of stochastic differential equations in valuing the option, and then apply a numerical procedure to obtain the results. It must, however, be noted that using the stochastic differential equations approach in option valuation is the most complicated approach and requires a measure of background in stochastic calculus (Miller \& Park, 2002).

While the discrete and closed form approaches can calculate the true real option, value based on market equilibrium theory, the stochastic differential equations produce mathematically correct option values. Barman and Nash (2007) and Cailao (2009) however noted that real estate professionals tend to avoid their use given the mathematical complexity associated with the method. The discrete and closed form approaches are perceived to be complicated due to the need for an understanding of some underlying financial theories and principles. The stochastic differential equations approach is often avoided due to its highly sophisticated mathematical inclination. In addition, the difficulty in explaining the underpinning theories of the approaches to investors or decision makers led to the development of the Monte Carlo simulation approach in evaluating real options. Hence, it appears that the discrete and closed form approaches and the differential equation approach appears complicated and confusing. The Monte Carlo simulation approach, however, uses common tools that are familiar to most real estate appraisers and investors.

\subsection{Monte Carlo Simulation}

In response to the challenges encountered with the use of the discrete and closed form approaches, researchers in the fields of engineering and decision sciences proposed the Monte Carlo simulation model (Miller \& Park, 2002; Barman \& Nash, 2007).

In Monte Carlo simulations, thousands of possible future outcomes are generated randomly, and the option value of the project under these instances are calculated. As with other real option methods, the value of the option is arrived at by differencing the project with the option and the project without the option. The model gives the appraiser greater flexibility in analysing real options with less financial computational rigour (Masunaga, 2007; Peter, 2012).

The significant advantages of the model include its ability to ascertain path dependency in real options (Masunaga, 2007), how it incorporates identified sources of uncertainty, how it represents outcomes graphically, and how it 
affords a more transparent analysis of results that is easy for investment decision makers to comprehend (Kim, 2008). However, a major demerit of the Monte Carlo based approach is that it might not always be possible to estimate true real option value mainly because of the arbitrary assumption of a single risk-adjusted discount rate. This could lead to either underestimation or overestimation of the real option value. However, this challenge can be overcome by incorporating the risk neutral dynamics into the Monte Carlo analysis (Masunaga, 2007; Kim, 2008; Cailao, 2009). The Monte Carlo simulation can also be used with other financial models which do not use this strict assumption.

Having examined the various real options models, the applicability of any of the models appears largely dependent on the appraiser and the sophistication of the investors. While it may also be evident that investment decision may still be based on naïve/heuristic approaches due to the apparent lack of sophistication of the appraiser or some other inherent factors, it can still be noted that appraisers and investors still incorporate some form of flexibility into their investment decisions. The study of Barman and Nash (2007) noted that investment appraisers incorporate flexibility into their decision-making process based on intuition and expert judgement. Although these naïve methods of flexibility might not always give optimal results, the real options models provide a means through which investors can incorporate flexibility through a standard quantitative process, thereby achieving optimal outputs for investment decisions.

However, it must be noted that the real options approach is not a silver bullet; there are inherent limitations with the approach. Bozbay et al. (2004) noted that there are tendencies for miscalculation and misuse of the ROA which could lead to wrong appraisal estimates. Furthermore, the authors noted that ROA is susceptible to model risk, that is, the risk associated with the use of an incorrect model, incorrect inputs in correct models, or the incorrect use of a correct model, all of which could lead to the problem of 'garbage-ingarbage-out'. Chance and Peterson (2002) posited that since the value of the underlying assets can be subjectively influenced by exercising or not exercising the option, the real value of the option may not be an objective estimate. Other criticisms of ROA as noted by Chance and Peterson (2002) include the inability to explain absurd valuations and failure to meet assumptions such as lognormality, randomness and known and constant volatility. However, while these criticisms have varying effects on the outcome of the appraisal estimate and may give cause for concern, the criticisms only suggest that investment appraisers adopting the real options framework must keep these in mind and demonstrate some form of caution when adopting ROA.

\section{Factors Influencing the Adoption of Real Option Models}

While investment decisions are fraught with uncertainties about future market conditions, literature is replete with benefits of ROA in managing the effects of these uncertainties with regards to the investment appraisal. However, it appears that investment appraisers are somewhat hesitant to employ ROA (Block, 2007; Kjærland, 2009; Bravi \& Rossi, 2012). Busby and Pitts (1997) 
noted that while very few investment appraisers were aware of real options, most appraisers and decision makers only agreed intuitively with the qualitative recommendations of the model and did not empirically employ the models in RED appraisal. It appears that some factors influence the adoption or otherwise of the ROA by RED appraisers.

Busby and Pitts (1997) alluded to the fact that organisational constraints, industry regulations, special legislation and preference for the traditional appraisal methods are major factors determining the choice of appraisal methods. Furthermore, Lander and Pinches (1998) identified the following as factors inhibiting the adoption of real options approaches in RED. These are difficulty in understanding and implementing, constraints subject to assumptions, lack of mathematical skills, restrictive modelling assumptions, and increasing complexity. Uher and Toakley (1999) noted that inadequate knowledge, inadequate skill, ignorance, negative attitude, lack of understanding of potential benefits, and fear of working with probability and statistics as significant factors influencing the choice of methods adopted in the appraisal of RED.

Furthermore, a study by Block (2007) identified lack of support from top management as a key reason for why the real option was not being wholly adopted by most investment appraisers. Other reasons as identified by Block (2007) include a preference for DCF methods, a high degree of sophistication required for ROA and that real option encourages excessive risk-taking. Hence, investment appraisers tend to shy away from the use of ROA. Kjærland (2009) noted that the limited use of real option arose from the complexity of the model, the initial eagerness to embrace a modern method and the resultant disappointment and abandonment, complicating factors when adapting financial options theory to real-life scenarios, and a lack of tangible underlying assets. In addition, Dyson and Oliveira (2007) argued that a disadvantage of the ROA is its reliance on quantitative data. It must be noted that there is inherent difficulty in obtaining this data especially in emerging markets like Nigeria. The study of Carmichael et al. (2011), while affirming the arguments of Dyson and Oliveira (2007), argued that appraisers' hesitancy toward ROA derives from the lack of data required as input variables and unintuitive nature of ROA. Other factors influencing the choice of appraisal techniques especially among appraisers in emerging markets include; lack of expertise, lack of sound data, and giving priority to experience (Nnamani, 2017).

Thus, the above argument shows that the factors influencing the choice of ROA as an appraisal technique could be grouped under five broad headings. These are:

1. Individual-based factors; inadequate mathematical skills, ignorance/inadequate awareness about real option methodology and preference for rule of thumb methods.

2. Market-based factors; constraints arising from local operating/market environment and level of market maturity. 
3. Client-based factors; inadequate sophistication from investors and inadequate demand by investors/clients.

4. Firm based factors; inadequate support/interest from top management personnel, management conveniences and industry regulations.

5. Data-related factors; need for good and reliable historical data and mathematical complexity in terms of data requirements.

This also suggests that despite the potential of real option in managing uncertainty in RED, it appears that ROA remains largely ignored and infrequently used by firms and investment appraisers. While literature has alluded to an array of factors apparently influencing its adoption, it must be noted that given the need to boost investors' confidence in the appraisal output and reduce losses associated with RED, the increasing sophistication of investors and the highly dynamic market fundamentals/variable inputs are a standard features of most emerging markets. Real estate investment appraisers could be encouraged to embrace methods that are more quantitative, in which appraisal estimates are realistic.

\section{Conclusion}

RED is subject to a varied number of interrelated circumstances, events and influences beyond the control of the investor. These circumstances often lead to uncertainty in the expected returns. Thus, forecasting profitability or a decision to invest might become 'a game of chance' if uncertainty and the investor's ability to alter the course of development are not adequately incorporated into the decision-making process. Given the importance of RED appraisal, the irreversible nature of RED and its significant capital involvement, the need for a realistic and meaningful RED appraisal estimates becomes apparent.

Investment in RED is dictated by the forces of demand and supply, which compels the need for appraisal of projected cash flows to determine the project's profitability or otherwise. However, appraisal estimates are often affected by different sources of uncertainty, which could be from sources within the project, the space market, or a combination of both external and internal project factors. These factors cast a shadow on the realisation of profitability from the investment outlay, thereby necessitating the need to account for these sources of uncertainty. Thus, profitability is dependent on the effective management of uncertainty.

In managing the effects of uncertainty in RED appraisal, on the one hand, traditional approaches have been criticised for their inability to adequately capture the effects of uncertainty, owing to the static rules and the possibility of the underlying inputs varying over the life of the investment. On the other hand, the probabilistic models do not adequately reflect the options that are inherent in an investment outlay. Thus, there is a need for the incorporation of contemporary approaches, such as ROA, in RED appraisal.

Where the investment appraiser makes use of ROA, the investment outlay is better suited to adjust to the unfolding realities of the space market, the 
economy, or the project itself, thereby ensuring profitability of returns or reducing likely losses. Thus, with ROA, it is expected that the investor can decide on a number of pathways, such as growth, abandonment, deferral or modification, based on prevailing realities. This portfolio of options could be exercised either in combination or individually, and at different periods over the life of the investment. This will ultimately guarantee optimal investment decision with regards to RED and enhance the reliability of appraisal output.

The above conclusion is particularly relevant to emerging African real estate markets where studies have suggested that risk analysis and uncertainty management in RED were still analysed without recourse to robust and sophisticated appraisal techniques (Ogunba, 2004; Olaleye et al., 2007; Nnamani, 2017). Further, there are particular volatilities associated with economic and other market indices in African markets resulting in high level of investment risk and uncertainty. Consequently, the adoption of ROA in RED appraisal could be relevant for these developing economies. Existing concerns, in the form of poor/inaccessible data, the level of appraisers' sophistication and other markets, as well as related institutional issues, must, however be critically examined for there to be an effective adoption of ROA in RED appraisal. This will ensure more realistic appraisal output and increasing investors' confidence in the appraisal practice.

In summary, against the need to provide information to stakeholders, this paper provides an overview of the varying forms and sources of uncertainty in the RED appraisal. The study also explored various methods employed in the management of uncertainty. A major conclusion from the review of the literature is that the RED appraiser and other institutional factors are major determinants in the choice of methods adopted in the management of uncertainty in RED appraisal. A general position from the review of studies showed a preference for the real options model. This could enhance the reliability of appraisal outputs and ensure best practices. However, given that the study has not empirically investigated the perspectives of RED appraisers to the management of uncertainty in RED, the discussion herein presented needs to be seen as a theoretical approach to the management of uncertainty. The study could serve as a guide for a broader empirical investigation into the management of uncertainty and the factors influencing the choice of ROA in RED appraisals.

\section{Acknowledgements:}

The authors wish to acknowledge the contributions of the reviewers who made significant contributions to the initial and the current versions of the manuscript.

\section{References}

Akakandelwa, N. (2014). Analysing Option Values to Delay Development of Land in Windhoek, Namibia. Journal of African Real Estate Research, 1, pp.5-20. 
Andalib, M. S., Tavakolan, M., and Gatmiri, B. (2016). Analysing the barriers influencing the application of real options in the construction industry. Construction Research Congress, pp.1823-1833.

Aughenbaugh, J. M., and Paredis, C. J. J. (2006). Why are intervals and imprecision important in engineering design? NSF Workshop on Reliable Engineering Computing.

Bannerman, S. (1993). A framework for improved development appraisals in developing countries. Journal of Property Research, 10(2), pp.135-145.

Barman, B., and Nash, K. E. (2008). A streamlined real options model for real estate development, Doctoral Thesis, Massachusetts Institute of Technology.

Black F, and Scholes, M. (1973). The Pricing of Options and Corporate Liabilities. Journal of Political Economy, 81, pp.637-659.

Block, S. (2007). Are "real options" actually used in the real world? The Engineering Economist, 52(3), pp.255-267.

Blokpoel, S. B., Reymen, I. M. M. J., and Dewulf, G. P. M. R. (2005). Uncertainty management in real estate development: studying the potential of the SCRUM design methodology, In: 3rd International Conference on Innovation in Architecture, Engineering and Construction -AEC2005, June 5-7, Rotterdam, pp.851-862.

Bowman, E.H., and Moskowitz, G.T. (2001). Real options analysis and strategic decision making. Organization Science, 12(6), pp.772-777.

Bozbay, M, Yau, H., Goadrich, L., Hsieh, P.F. and Sumanth, S (2004) Getting Real about Real Options, Retrieved from www.laura.goadrich.com/classWork/Option.ppt [8th August, 2017].

Brandão, L. E., and Dyer, J. S. (2003). Valuing real options projects in incomplete markets with correlated uncertainties, Austin: University of Texas.

Bravi, M., and Rossi, S. (2012). Real estate development, highest and best use and real options, XLI Incontro di Studio del Ce.S.E.T., pp.479-498.

Brealey, R. A., Myers, S. C., Allen, F., and Mohanty, P. (2012). Principles of corporate finance, Tata McGraw-Hill Education.

Busby, J. S., and Pitts, C. G. C. (1997). Real options in practice: an exploratory survey of how finance officers deal with flexibility in capital appraisal. Management Accounting Research, 8(2), pp.169-186.

Byrne, P. (1998). Risk, Uncertainty and decision-making in property development, E \& FN Spon, London.

Cailao, A. P. (2009). A real options case study: The valuation of flexibility in the World Trade Centre redevelopment. Doctoral Thesis, Massachusetts Institute of Technology.

Carmichael, D. G., Hersh, A. M., and Parasu, P. (2011). Real options estimate using probabilistic present worth analysis. The Engineering Economist, 56(4), pp.295-320.

Chalupnik, M. J., Wynn, D. C., and Clarkson, P. J. (2009). Approaches to mitigate the impact of uncertainty in development processes, In $D S 58$ 1: Proceedings of ICED 09, the 17th International Conference on Engineering Design, Vol. 1, Design Processes, Palo Alto, CA, USA, 24.27.08. 2009.

Chance, D. M., and Peterson, P. P. (2002). Real Options and Investment Valuation, The CFA Digest. 
Cho, J. (2008). Issues and Challenges of agile software development with SCRUM. Issues in Information Systems, 9(2), pp.188-195.

Copeland, T., Koller, T., Murrin, J., and McKinsey. (2010). Valuation: Measuring and Managing the Value of Companies, New York, John Wiley \& Sons.

Cox, J. C., Ross, S. A., and Rubinstein, M. (1979). Option pricing: A simplified approach. Journal of financial Economics, 7(3), pp.229-263.

Dixit, A. K, and Pindyck, R. S. (1994). Investment under uncertainty, Princeton University Press.

Dyson, R., and Oliveira, F. S. (2007). Flexibility, robustness and real options, Wiley, Chichester, pp.343-366.

Ekpenyong, E. (2015). Nigeria: an analysis of the challenges and prospects in real estate development in Nigeria, Retrieved from http://www.mondaq.com [April, 2016].

Feinstein, S. P., and Lander, D. M. (2002). A better understanding of why NPV undervalues managerial flexibility. The Engineering Economist, 47(4), pp.418-435.

Geltner, D. (2007). Commercial real estate analysis and investments, Thompson South-Western.

Geltner, D. and Miller, N. G. (2001). Commercial real estate analysis and investments, First edition upper saddle river, N. J., Prentice Hall Mason.

Guma, A. C. (2008). A real options analysis of a vertically expandable real estate development. M.Sc. Thesis, Massachusetts Institute of Technology.

Haimes, Y. Y. (1998). Risk modelling, assessment, and management, Wiley Series in Systems Engineering. Wiley, New York.

Hargitay, S. E. and Yu, S. M. (1993). Property Investment Decisions: a quantitative approach, Routledge.

Hillson, D. (2004). Effective opportunity management for projects: Exploiting positive risk, New York: Marcel Decker.

Kahneman, D. and Tversky, A. (1982). Variants of uncertainty. Cognition, 11, pp.143-157.

Kandel, E., and Pearson, N. D. (2002). Option value, uncertainty, and the investment decision. Journal of Financial and Quantitative Analysis, 37(03), pp.341-374.

Kim, K. (2008). Real options: a way to deal with market uncertainty in real estate development projects. M.Sc. Thesis, Massachusetts Institute of Technology.

Kjærland, F. (2009). Valuation of generation assets-a real option approach. Doctoral Thesis, Bodø Graduate School of Business.

Knight, F. H. (1921). Risk, uncertainty and profit, New York: Hart, Schaffner and Marx.

Kumar, R. (2016). Real options valuation. Valuation, 1(1), pp.227-236.

Lander, D. M., and Pinches, G. E. (1998). Challenges to the practical implementation of modelling and valuing real options. The Quarterly Review of Economics and Finance, 38 (Special Issue), pp.537-567.

Lina, Z., \& Dan, S. (2012). Research on combining scrum with CMMI in small and medium organizations. Computer science and electronics engineering (iccsee), 2012 international conference. 554-557). 
Loewenstein, G. F., Hsee, C. K., Weber, E. U. and Welch, N. (2001). Risk as Feelings. Psychological Bulletin, 127(2), pp.267-286.

Loizou, P. and French, N. (2012). Risk and uncertainty in development: A critical evaluation of using the Monte Carlo simulation method as a decision tool in real estate development projects. Journal of Property Investment and Finance, 30(2), pp.198-210.

Luhmann, N. (1990). Technology, environment and social risk: a systems perspective. Industrial Crisis Quarterly, 4(3), pp.223-231.

Masunaga, S. (2007). A comparative study of real options valuation methods: economics-based approach vs. engineering-based approach. M.Sc. Thesis, Massachusetts Institute of Technology.

Mckean, H. P. (1965). Appendix: A Free Boundary Problem for the Heat Equation Arising from a Problem in Mathematical Economics. Industrial Management Review, 6, pp.32-39.

McManus, H., and Hastings, D. (2005). A framework for understanding uncertainty and its mitigation and exploitation in complex systems. INCOSE International Symposium, 15(1), pp.484-503.

Merton, R. C. (1973). Theory of Rational Option Pricing. Bell Journal of Economic Management Science, 4, pp.141-183.

Miller, L. T., and Park, C. S. (2002). Decision making under uncertainty - real options to the rescue? The Engineering Economist, 47(2), pp.105-150.

Morano, P., Tajani, F., and Manganelli, B. (2014). An application of Real Option Analysis for the assessment of operative flexibility in the urban redevelopment. WSEAS Transactions on Business and Economics, 11(1), pp.476-487.

Mun, J. (2002). Real options analysis tools and techniques for valuing strategic investments and decisions, John Wiley \& Sons, Inc., Hoboken, New Jersey.

Mun, J. (2006). Real options analysis versus traditional DCF valuation in layman's term, John Wiley \& Sons, Inc., Hoboken, New Jersey.

Nnamani, O. C. (2017). Application of Risk Management Techniques in Property Development Projects in Nigeria: A Review. Retrieved from: library.eres. org/eres2017/paperupload/P_20170106050949_343.pdf

Ogunba, O. A. (2004). Globalisation and risk management in development appraisal: challenges before Nigeria. Globalisation and Construction, pp.689-700.

Olaleye, A. (2008). Property market nature and the choice of property portfolio diversification strategies: The Nigeria experience. International Journal of Strategic Property Management, 12(1), pp.35-51.

Olaleye, A., Aluko, B. T., \& Ajayi, C. A. (2007). Factors influencing the choice of property portfolio diversification evaluation techniques in Nigeria. Journal of Property Investment \& Finance, 25(1), pp.23-42.

Pandey, I. M. (1999). Financial Management, Eighth edition. Vikas publishing house, PVT Ltd, New Delhi.

Pearson, J. R., and Wittels, K. S. (2008). Real options in action: vertical phasing in commercial real estate development. M.Sc. Thesis, Massachusetts Institute of Technology.

Pender, S. (2001). Managing incomplete knowledge: Why risk management is not sufficient. International Journal of Project Management, 19(2), pp.79-87. 
Perminova, O., Gustafsson, M., and Wikström, K. (2008). Defining uncertainty in projects - a new perspective. International Journal of Project Management, 26(1), pp.73-79.

Peter, J. (2012). Modelling Uncertainty and Flexibility in the Financial Analysis of a Real Estate Development Project in Switzerland. Doctoral Thesis, ETH Zurich.

Peters, E. and Slovic, P. (1996). The role of affect and worldviews as orienting dispositions in the perception and acceptance of nuclear power. Journal of Applied Social Psychology, 26(16), pp.1427-1453.

Peters, E., Burraston, B., and Mertz, C. K. (2004). An emotion-based model of risk perception and stigma susceptibility: Cognitive appraisals of emotion, affective reactivity, worldviews, and risk perceptions in the generation of technological stigma. Risk Analysis, 24, pp.1349-1367.

Pindyck, R. S. (1991). Irreversibility, uncertainty, and investment. Journal of Economic Literature, 29, pp.1110 - 1148.

PricewaterhouseCoopers. (2014). Real estate 2020: building the future. Retrieved from: https://www.pwc.com/sg/en/real-estate/assets/pwc-realestate-2020-building-the-future.pdf [22 June, 2018].

PricewaterhouseCoopers and the Urban Land Institute. (2013). Emerging Trends in Real Estate 2014, Washington, D.C.: PwC and the Urban Land Institute.

Raftery, J. (2003). Risk analysis in project management, Routledge.

Reymen, I. M., Dewulf, G. P., and Blokpoel, S. B. (2008). Framework for managing uncertainty in property projects. Building Research \& Information, 36(6), pp.580-592.

Rodrik, D. (1991). Policy uncertainty and private investment in developing countries. Journal of Development Economics, 36(2), pp.229-242.

Săcui, V., and Dumitru, F. (2012). The strategic options in investment projects valuation. Anale. Seria Stiinte Economice. Timisoara, 18, pp.494-499.

Samuelson, P. A. (1965). Rational Theory of Warrant Pricing. Industrial Management Review, 6, pp.13-31.

Sattarnusart, W. (2012). Real options in real estate development investment. M.Sc. Thesis Stockholm, Sweden.

Saunders, F. C., Gale, A. W., and Sherry, A. H. (2015). Conceptualising uncertainty in safety-critical projects: A practitioner perspective. International Journal of Project Management, 33(2), pp.467-478.

Schwaber, K. (1996). SCRUM development process. Proceedings of ACM SIGPLAN on Objected-Oriented Programming, Systems, Languages, \& Applications (OOPSLA '96), San Jose, California.

Schwaber, K., \& Beedle, M. (2002). Agile software development with Scrum, Upper Saddle River, NJ: Prentice Hall

Slade, M. E. (2001). Valuing managerial flexibility: An application of realoption theory to mining investments. Journal of Environmental Economics and Management, 41, pp.193-233.

Slovic, P. (1999). Trust, emotion, sex, politics, and science: Surveying the riskassessment battlefield. Risk analysis, 19(4), pp.689-701.

Slovic, P. and Peters, E. (2006). Risk Perception and Affect. Current Directions in Psychological Science, 15, pp.322 -325. 
Slovic, P., Finucane, M. L., Peters, E. and MacGregor, D. G. (2004). Risk as Analysis and Risk as Feelings: Some Thoughts about Affect, Reason, Risk, and Rationality. Risk Analysis, 24(2), pp.311-322.

Smit, H. T., and Trigeorgis, L. (2003). Real Options: Examples and principles of valuation and strategy, In McCahery, J. and Renneboog, L. (Eds.), Venture Capital Contracting and the valuation of high tech firms. Oxford University Press.

Smithson, M. (2008). The many faces and masks of uncertainty, Uncertainty and risk: Multidisciplinary perspectives, Earthscan Publications Ltd.

Tamayo-Torres, I., Ruiz-Moreno, A., and Verdú, A. J. (2010). The moderating effect of innovative capacity on the relationship between real options and strategic flexibility. Industrial Marketing Management, 39(7), pp.11201127.

Throupe, R., Sewalk, S., Zhong, J., and Huo, C. (2012). Real option analysis: a switching application for mixed-use real estate development. Pacific Rim Property Research Journal, 18(3), pp.277-292.

Tomas, I., and Višić, J. (2009). Real option analysis-decision making in volatile environment, In Symposium on operational research.

Trigeorgis, L. (1993). Real options and interactions with financial flexibility. Financial management, 22(3), pp.202-224.

Trigeorgis, L. and Smith, H. T. J. (2004). Strategic Investment: Real Options and Games, New York: Princeton University Press.

Uher, T. E., and Toakley, A. R. (1999). Risk management in the conceptual phase of a project. International Journal of Project Management, 17(3), pp.161-169.

Ustinovičius, L., Migilinskas, D., Tamošaitienè, J., and Zavadskas, E. K. (2007). Uncertainty analysis in construction project's appraisal phase. Modern Building Materials, Structures and Techniques, 1, pp.3-10.

Walters, C., and Giles, T. (2000). Using real options in strategic decision making, London Economics. Otoño.

Ward, S., and Chapman, C. (2003). Transforming project risk management into project uncertainty management. International Journal of Project Management, 21(2), pp.97-105.

Yeo, C. (2012). Primer on risk analysis, decision making under uncertainty, CRC, Boca Raton.

Yeo, K. T., and Qiu, F. (2003). The value of management flexibility - a real option approach to investment evaluation. International Journal of Project Management, 21(4), pp.243-250. 